\title{
Thermal Effects in Suspended RF Spiral Inductors
}

\author{
H. Sagkol, Student Member, IEEE, S. Sinaga, J. N. Burghartz, Fellow, IEEE, B. Rejaei, and A. Akhnoukh
}

\begin{abstract}
Self-heating effects on integrated suspended and bulk spiral inductors are explored. A dc current is fed through the inductors during measurement to emulate dc and radio frequency power loss on the inductor. A considerable drop in $Q$ by $\sim 18 \%$ at $36.5 \mathrm{~mW}$ is observed for suspended coils with $3-\mu \mathrm{m}$ aluminum metallization compared to reference inductors on bulk-Si. Simulations in Ansoft's ePhysics indicate that, due to the thermal isolation of the suspended coil, the power loss from resistive self-heating in the metal has to be transferred outwards through the metal turns. This also results in a thermal time constant. This time constant is measured to be $\sim 10 \mathrm{~ms}$, meaning that it can affect power circuits operating in pulsed mode.
\end{abstract}

Index Terms-Micromachining, radio frequency (RF) circuits, spiral inductor, suspended inductor, thermal effects.

\section{INTRODUCTION}

$\mathbf{O}$ $\mathrm{N}$-CHIP spiral inductors are starting to replace their offchip counterparts in radio frequency (RF) circuits, driven by the need for smaller size and lower cost. Inductors on conventional silicon ( $\mathrm{Si}$ ) substrates, however, considerably suffer from RF substrate losses, thus limiting the inductor's quality factor $(Q)$ [1]. Local removal of the Si underneath, i.e., suspension of the coil, is an obvious solution to eliminate such substrate losses. This technique has therefore been used in various approaches to demonstrate record- $Q$ results from the first attempts to inductors on Si substrates until today [2]-[7].

In contrast to the common inductor $S$-parameter characterization at a very small signal power level $(-20$ to $0 \mathrm{dBm})$, in real circuit applications often large RF signals or dc bias currents are passed through an inductor [8]. Since the removal of the Si not only reduces the substrate losses but also isolates the suspended coil thermally, self-heating effects can result in a dramatic change in $Q$ associated with a considerable time constant. Only the mechanical aspects of these thermal effects have been discussed so far [2], [4], [9].

In this letter we present, to our knowledge for the first time, a detailed investigation of the effect of self-heating on the electrical characteristics of integrated spiral inductors in general, and of suspended inductors in particular.

\section{INDUCTOR DESIGN}

Spiral inductors ranging from 1 to $10 \mathrm{nH}$ were designed and fabricated in an in-house bipolar process with two alu-

Manuscript received March 30, 2005; revised May 17, 2005. The review of this letter was arranged by Editor M. Ostling.

The authors are with the Laboratory of High-Frequency Technology and Components (HiTeC), Delft Institute of Microelectronics and Submicrontechnology (DIMES) and Department of Electrical Engineering, Mathematics and Computer Science (EEMCS), Delft University of Technology, 2600 GA Delft, The Netherlands (e-mail: h.sagkol@ewi.tudelft.nl).

Digital Object Identifier 10.1109/LED.2005.852524

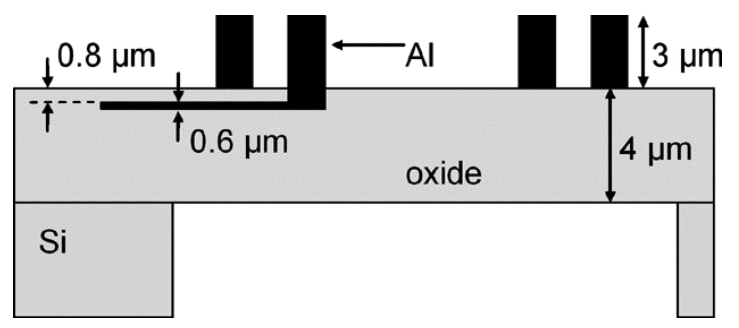

Fig. 1. Cross section of the suspended inductor.

minum (Al) interconnect layers with a thickness of 0.6 and $3 \mu \mathrm{m}$ (Fig. 1). A 4- $\mu \mathrm{m}$-thick oxide layer was used to isolate the coils from the Si substrate $(5 \Omega-\mathrm{cm}$; Fig. 1.). The $\mathrm{Si}$ underneath was locally removed from the backside with deep reactive ion etching to suspend the coils (Fig. 1). Reference inductors on bulk-Si were fabricated on the same wafer. Results for a three-turn 5-nH inductor (diameter $=500 \mu \mathrm{m}$, metal width $=25.3 \mu \mathrm{m}$, metal spacing $=5.8 \mu \mathrm{m}$, underpass width $=32 \mu \mathrm{m}$, with $323 * 3 \mu \mathrm{m}$ via contacts) is presented as an example. The other inductors show similar effects.

\section{RESUlTS AND DISCUSSION}

The inductance $L$ and quality factor $Q$ of the coils were extracted from small-signal $S$-parameter measurements carried out on a HP8510C network analyzer at $+10 \mathrm{dBm}$ power level. In order to emulate the effect of the mentioned high power levels in RF circuits (both RF and dc), a dc bias current was fed through the coils. The measurements were repeated several times on the same structure in order to ensure reproducibility and to rule out any permanent damage during operation.

Fig. 2(a) shows the $Q$ 's of the suspended and reference 5-nH inductors as a function of frequency for different bias currents (0 to $100 \mathrm{~mA}$ in $20-\mathrm{mA}$ steps). Increasing the dc bias clearly reduces the peak value of $Q\left(Q_{\max }\right)$ and the slope of the curves below the frequency of $Q_{\max }\left(f\left(Q_{\max }\right)\right)$. At a bias current of $100 \mathrm{~mA}$, a drop of $Q_{\max }$ as high as $\sim 18 \%$ was observed. Since at frequencies much below $f\left(Q_{\max }\right)$ the $Q$ depends largely on the dc series resistance $\left(R_{\mathrm{dc}}\right)$ of the coil, i.e., $Q \approx \omega L / R_{\mathrm{dc}}$, and $L$ changes less than $1 \%$ [Fig. 2(b)], it can be concluded that the thermal effect on $R_{\mathrm{dc}}$ is mainly responsible for the decay of $Q$. Clearly, the dc power dissipated in the metal windings of the inductor raises the temperature, leading to an increase in metal resistivity. No such effect was observed for the reference inductors, in which an efficient heat transfer to the Si substrate can take place.

Table I lists the measured $Q_{\max }$ and $R_{\mathrm{dc}}$ values at different dc bias levels for the suspended inductor. The experimental value of $R_{\mathrm{dc}}$ can be used to estimate the dc power dissipation $P_{\mathrm{dc}}=$ 


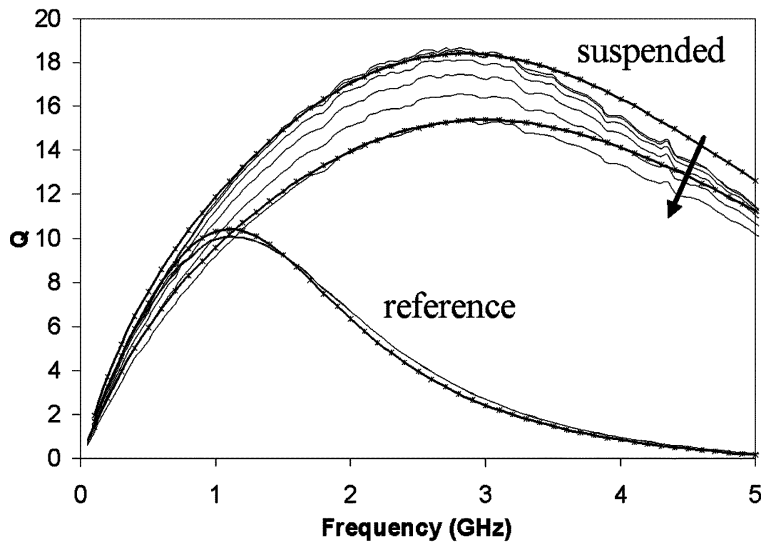

(a)

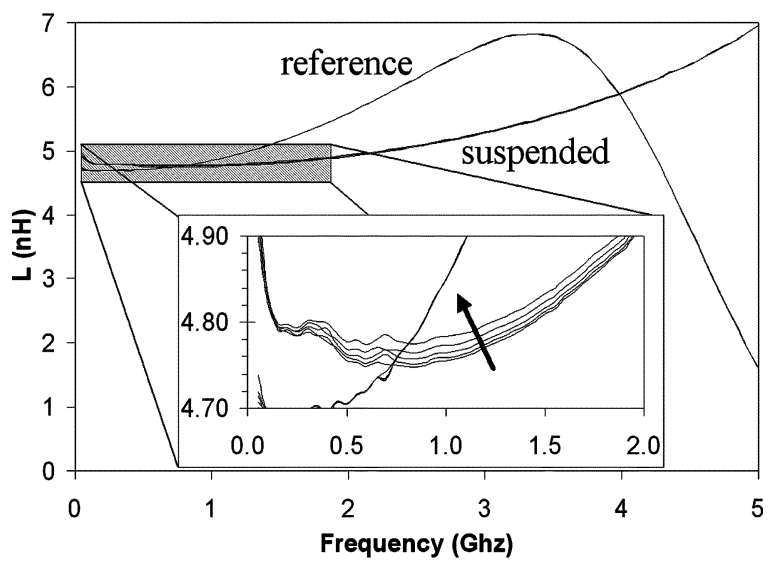

(b)

Fig. 2. Measured (a) quality factor (Q) and (b) inductance $(L)$ versus frequency of suspended and bulk reference inductors at a dc current raised from 0 to $100 \mathrm{~mA}$ in $20 \mathrm{~mA}$ steps (Arrows; Table I). The $Q$ of the reference case in (a) does not change for different dc currents, leading to overlapping curves. Ansoft HFSS simulation results of the suspended coil for 0 and $100 \mathrm{~mA}$ are included, as well as that of the reference structure (markers). Good agreement between the simulation and experimental results is observed.

TABLE I

Measured DC Resistance and $Q_{\max }$ Values for Given CurRent STEPS

\begin{tabular}{lrrrcrr}
\hline \hline$I(\mathrm{~mA})$ & 0 & 20 & 40 & 60 & 80 & 100 \\
\hline$P_{\mathrm{DC}}(\mathrm{mW})$ & 0 & 1.2 & 4.8 & 11.3 & 21.2 & 36.5 \\
\hline $1 / R_{\mathrm{DC}}$ & 0.340 & 0.339 & 0.333 & 0.319 & 0.302 & 0.274 \\
\hline$\Delta 1 / R_{\mathrm{DC}}(\%)$ & & 0.39 & 2.05 & 6.22 & 11.29 & 19.49 \\
\hline$T \operatorname{emp}\left({ }^{\circ} \mathrm{C}\right)$ & 20 & 20.7 & 24.7 & 35.2 & 49.2 & 76 \\
\hline $\mathrm{Q}_{\max }$ & 18.65 & 18.54 & 18.14 & 17.46 & 16.56 & 15.34 \\
\hline$\Delta \mathrm{Q}_{\max }(\%)$ & & 0.61 & 2.75 & 6.83 & 11.22 & 17.77 \\
\hline \hline
\end{tabular}

$I^{2} R_{\mathrm{dc}}$ in the coil. It was not possible in our laboratory, however, to directly measure the temperature and its variation across the surface of the spiral, which is important for investigating the heat dissipation mechanism in the structure. The thermal properties of the structure were therefore determined by using the simulation tool ePhysics of Ansoft Corporation, including thermal conduction through metal, $\mathrm{Si}$, and air, as well as convection. A distributed resistive heat source was assigned to the spiral coil with a power equal to the dc power $P_{\mathrm{dc}}$. The results obtained for the temperature distribution over the spiral structure are shown in Fig. 3. While away from the metal pads the temperature of the spiral is found to be elevated to nearly $100^{\circ} \mathrm{C}$, it is almost at room temperature $\left(20^{\circ} \mathrm{C}\right)$ near the pads. This leads to the

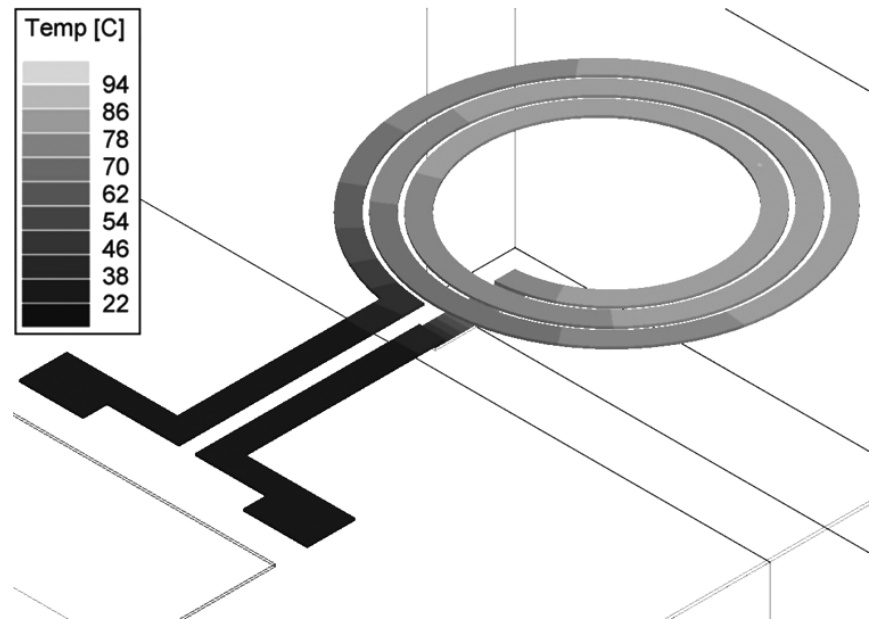

Fig. 3. Temperature distribution of the spiral simulated by Ansoft ePhysics.

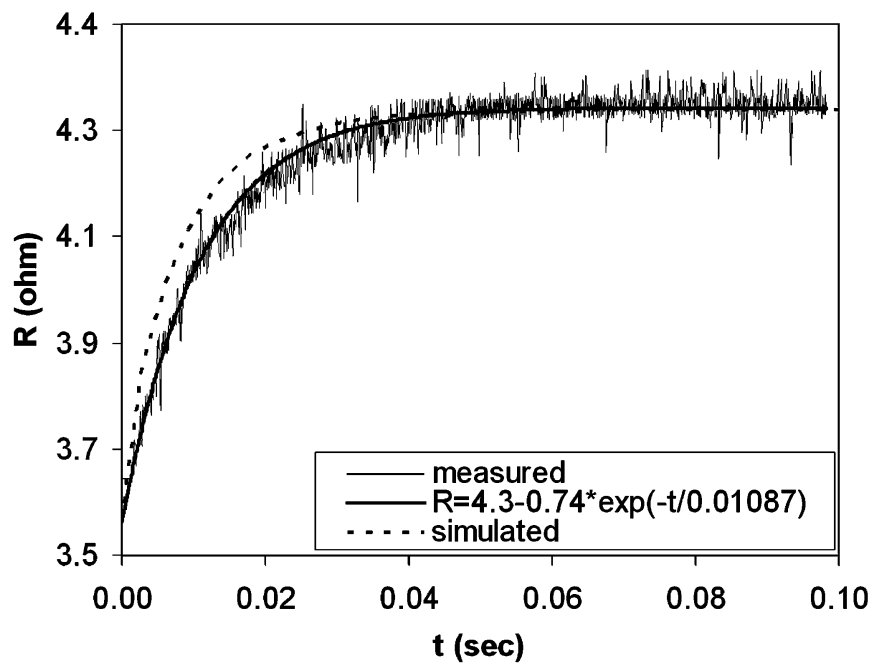

Fig. 4. Transient measurement and simulation of the dc resistance. Also a curve fitting to the measurement is shown.

conclusion that contact pads/lines and the underlying Si effectively act as a heat sink and that heat conduction and convection through air has a comparably small effect. This conclusion is in reasonable agreement with the average coil temperature calculated from the change in coil resistance with temperature [Table I: $76{ }^{\circ} \mathrm{C}$ calculated average versus $94{ }^{\circ} \mathrm{C}$ simulated peak Temperature: (Fig. 3) at $100 \mathrm{~mA}$, i.e., $36.5 \mathrm{~mW}$ ].

The time to reach this temperature is critical, since most power circuits are switched on for short times to save power. If the switch-on period is of the order of the thermal time constant of the coil structure, the $Q$ will be changing throughout the duty cycle of the circuit. To clarify this point, we have extracted the thermal time constant of the coil by monitoring $R_{\mathrm{dc}}$ over time after applying a fast voltage pulse. In spite of the measurement noise, a clear trend is visible (Fig. 4). For comparison, the results of a transient thermal simulation using ePhysics are shown as well. Exponential curve fitting applied to the oscilloscope trace yields a time constant of $\sim 10 \mathrm{~ms}$. This is comparable to the operating time of switched power circuits, indicating the significance of this observation. Therefore, self-heating effects on $Q$ can affect the operating point of RF power circuits that 
include thermally isolated inductors, such as the matching section of a power amplifier where matching will be distorted in time leading to output power fluctuations.

\section{CONCLUSION}

We have shown that micromachined inductors suffer from significant self-heating effects. Self-heating occurs fast enough to influence RF circuits that are operated in pulse mode by changing the $Q$ of a thermally isolated inductor. Hence, when high RF or dc power levels are involved, measures have to be taken to facilitate the transfer of heat away from the coil. A possible solution is the use of very thick metal for reduced thermal resistance of the coil or the consideration of inductors built on low-loss, yet thermally well conducting, substrates such as high resistivity silicon [10].

\section{ACKNOWLEDGMENT}

The authors wish to thank the ICP staff of DIMES for their helpful discussions on wafer processing, and Ansoft Co. for supplying ePhysics software for this project.

\section{REFERENCES}

[1] J. N. Burghartz and B. Rejaei, "On the design of RF spiral inductors on silicon," IEEE Trans. Electron Devices, vol. 50, no. 3, pp. 718-729, Mar. 2003.

[2] H. Lakdawala, X. Zhu, H. Luo, S. Santhanam, L. R. Carley, and G. K. Fedder, "Micromachined high-Q inductors in a $0.18-\mu \mathrm{m}$ copper interconnect low-k dielectric CMOS process," IEEE J. Solid-State Circuits, vol. 37, no. 3, pp. 394-402, Mar. 2002.

[3] C. L. Chua, D. K. Fork, K. van Schuylenbergh, and J.-P. Lu, "Out-ofplane high-Q inductors on low-resistance silicon," J. Microelectromech. Syst., vol. 12, pp. 989-995, Dec. 2003.

[4] J. Chen, J. Zou, C. Liu, J. E. Schutt-Aine, and S.-M. Kang, "Design and modeling of a micromachined high-Q tunable capacitor with large tuning range and a vertical planar spiral inductor," IEEE Trans. Electron Devices, vol. 50, no. 3, pp. 730-738, Mar. 2003.

[5] M.-C. Hsieh, Y.-K. Fang, C.-H. Chen, and W.-K. Yeh, "Design and fabrication of deep submicron CMOS technology compatible suspended high-Q spiral inductors," IEEE Trans. Electron Devices, vol. 51, no. 3, pp. 324-330, Mar. 2004.

[6] H. Jiang, Y. Wang, J.-L. A. Yeh, and N. C. Tien, "On-chip spiral inductors suspended over deep copper-lined cavities," IEEE Trans. Microw. Theory Tech., vol. 48, no. 12, pp. 2415-2423, Dec. 2000.

[7] J. Y.-C. Chang, A. A. Abidi, and M. Gaitan, "Large suspended inductors on silicon and their use in a $2-\mu \mathrm{m}$ CMOS RF amplifier," IEEE Electron Device Lett., vol. 14, no. 5, pp. 246-248, May 1993.

[8] L. Besser and G. Rowan, Practical RF Circuit Design for Modern Wireless Systems Vol. 1\&2: Artech, Norwell, MA, 2003.

[9] P. J. Bell, N. Hoivik, V. M. Bright, and Z. Popovic, "Micro-bias-Tees using micromachined flip-chip inductors," in IEEE MTT-S Dig., vol. 1, Jun. 2003, pp. 491-494.

[10] B. Rong, J. N. Burghartz, L. K. Nanver, B. Rejaei, and M. v. d. Zwan, "Surface-passivated high-resistivity silicon substrates for RFICs," IEEE Electron Device Lett., vol. 25, no. 4, pp. 176-178, Apr. 2004. 